\title{
Evaluation of the performance of three advisory methods for nitrogen fertilization of sugar beet and potatoes
}

\author{
J. J. NEETESON \\ Institute for Soil Fertility, P.O. Box 30003, NL 9750 RA Haren, Netherlands \\ Received 23 February 1989; accepted 6 March 1989
}

\begin{abstract}
The performances of three different nitrogen fertilizer recommendation methods were retrospectively tested with data obtained from 150 fertilizer nitrogen trials with sugar beet and 98 trials with potatoes, which were conducted in the Netherlands in the period 19731982. The recommendations consisted of applying a fixed fertilizer nitrogen rate in all situations ( $126 \mathrm{~kg} \mathrm{~N}$ per ha for sugar beet and $286 \mathrm{~kg} \mathrm{~N}$ per ha for potatoes), the current Dutch method, which takes only the amount of mineral nitrogen present in the soil in early spring into account, and a refinement of the current method, which also takes soil type and recent applications of organic manures into account. On average, significantly lower amounts of fertilizer nitrogen were recommended with the current method. The difference from the other methods was on average $25 \mathrm{~kg} \mathrm{~N}$ per ha for sugar beet and $30 \mathrm{~kg} \mathrm{~N}$ per ha for potatoes. With the refined current method the highest crop yields were obtained, but the difference from the other methods was not significant and averaged only $0.3-0.4 \mathrm{t} \mathrm{ha}^{-1}$ for sugar beet and $0.1-0.2 \mathrm{t} \mathrm{ha}^{-1}$ for potatoes. The recovery of fertilizer nitrogen by the potato tubers was $2 \%$ higher with the current method than with the other methods. Based on these findings it is concluded that the current recommendation method is preferable to the other methods.
\end{abstract}

Keywords: crop yield, fertilizer nitrogen rate, nitrogen fertilizer recommendation, fertilizer nitrogen recovery, potatoes, sugar beet

\section{Introduction}

In the Netherlands the current nitrogen fertilizer recommendation method for sugar beet and potatoes is based on the amount of mineral nitrogen present in the soil in early spring (Anon., 1986). The larger the amount of soil mineral nitrogen, the lower the recommended application rate of fertilizer nitrogen. With two exceptions, viz. potatoes on sandy soils and sugar beet grown after green manure application, no account is taken in the recommendations of soil types and presence or absence of recently applied organic manures; these two factors have recently been shown to affect the response of sugar beet and potatoes to fertilizer nitrogen as well (Neeteson \& Zwetsloot, 1989). Therefore, the current recommendation method can be refined by taking soil type and organic manures into account. 
The purpose of this paper is to compare the performance of various methods of nitrogen fertilizer recommendation for sugar beet and potatoes. The method of applying a fixed rate for each crop in all situations without considering soil mineral nitrogen (Tinker, 1965; Dilz, 1981; Neeteson, 1985) is used as the reference method. The fixed-rate method is compared with the current nitrogen fertilizer recommendation method, which takes account of soil mineral nitrogen, and a method based on the results of Neeteson \& Zwetsloot (1989), which, in addition to soil mineral nitrogen, takes account of soil type and prior application of organic manures. The performances of the different methods are evaluated by determining the differences in recommended rates of fertilizer nitrogen, and in yields and recovery of fertilizer nitrogen from the response curves obtained in 150 sugar beet and 98 potato trials conducted earlier.

\section{Materials and methods}

\section{Experiments}

The performances of three nitrogen fertilizer recommendation methods were compared after the various recommended rates had been retrospectively applied to 150 sugar beet and 98 potato trials. It should be noted that the recommendations were made on the basis of the same trials. Unlike others (Sylvester-Bradley et al., $1987 \mathrm{a}, \mathrm{b})$, who used one-third of the trials available for constructing the recommendations and two-thirds for testing them, the whole body of trials available was used both for constructing and testing the recommendations, so as to base the recommendations on as many data as possible.

In the trials, soil mineral nitrogen was measured in various layers in early spring, and yield was measured at six or seven levels of fertilizer nitrogen. In the potato trials, also the amount of nitrogen in the tubers at harvest was measured. Details of the experimental design are given elsewhere (Neeteson \& Wadman, 1987; Neeteson \& Zwetsloot, 1989). When applicable, the recommended rates were calculated on the basis of the measured values of soil mineral nitrogen. The yield obtained with each recommendation was interpolated from the response curve of each individual trial. Modified exponential response curves (for sugar beet) or simple exponential response curves (for potatoes) were fitted to the measured yields (Neeteson \& Zwetsloot, 1989). For sugar beet the yields were expressed as fresh beet yields with a sugar content of $16 \%$ (Neeteson \& Wadman, 1987), and for potatoes as fresh tuber yields. The nitrogen recovery by the potato tubers was interpolated from the measured amounts of nitrogen in the tubers at the fertilizer nitrogen levels actually applied. The recovery was calculated according to the difference method, i.e. the difference between nitrogen uptake with and without fertilizer nitrogen application, expressed as a percentage of the amount of fertilizer nitrogen applied.

\section{Nitrogen fertilizer recommendations}

The recommendation methods show an increasing order of refinement: a fixed rate 


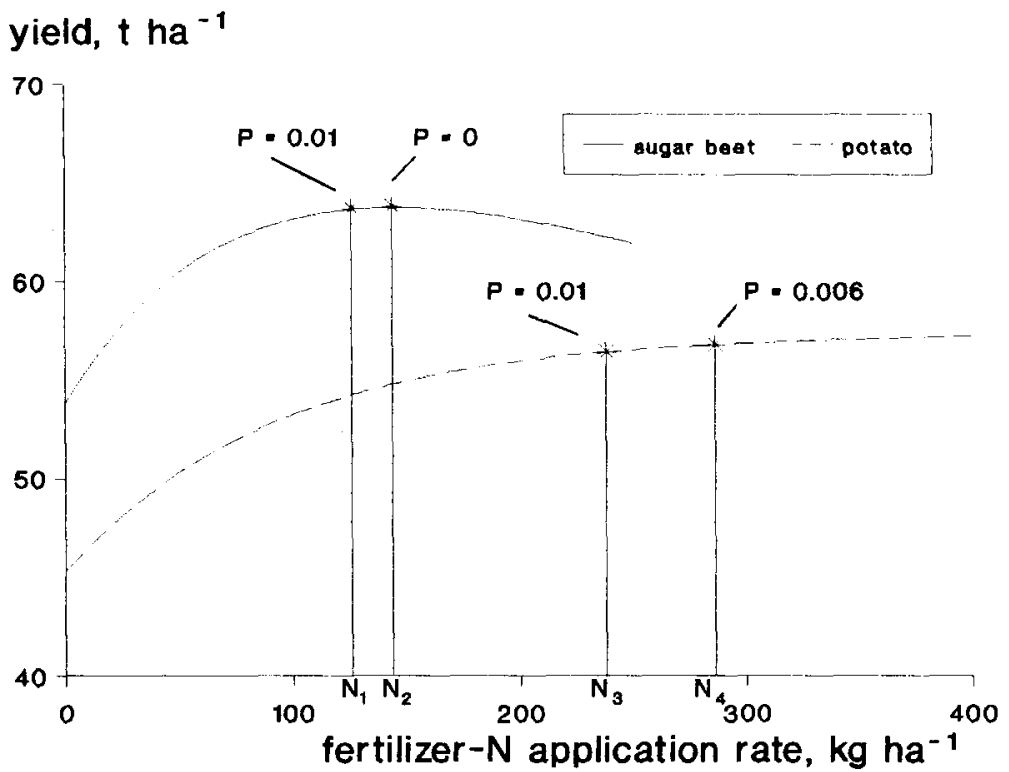

Fig. 1. Average response curves of sugar beet and potatoes. $\mathrm{N}_{1}$ and $\mathrm{N}_{2}=$ optimum application rate of fertilizer nitrogen for sugar beet when the monetary ratio $P$ is 0.01 and 0 , respectively. $N_{3}$ and $N_{4}=$ optimum application rate of fertilizer nitrogen for potatoes when the monetary ratio $\mathrm{P}$ is 0.01 and 0.006 , respectively.

in all situations (REC A), the current recommendation (REC B), and the recommendation based on the results of Neeteson \& Zwetsloot (1989) (REC C). The recommended rate with REC A was assumed to be the optimum fertilizer nitrogen rate as calculated from the average response curves (Fig. 1) of the 150 sugar beet and 98 potato trials which were used to test the recommendations. The ratio $P$ of the cost of $1 \mathrm{~kg}$ fertilizer nitrogen to the price of 1 tonne crop yield was assumed to be 0.01 for sugar beet and 0.006 for potatoes. These values are lower than those used previously (Neeteson \& Wadman, 1987) due to the current low costs of fertilizer nitrogen. The optimum rates were 126 (95\% confidence interval 121-132) $\mathrm{kg} \mathrm{N}$ per ha for sugar beet and 265 (95\% confidence interval 263-302) $\mathrm{kg} \mathrm{N}$ per ha for potatoes. The recommended rates with REC B were adapted from the recommendations given in Anon. (1986) in such a way that the ratio $P$ was 0.01 for sugar beet and 0.006 for potatoes. This implied $20 \mathrm{~kg} \mathrm{~N}$ per ha less for sugar beet $\left(\mathrm{N}_{2} \rightarrow \mathrm{N}_{1}\right.$ in Fig. 1) and $50 \mathrm{~kg} \mathrm{~N}$ per ha more for potato $\left(\mathrm{N}_{3} \rightarrow \mathrm{N}_{4}\right.$ in Fig. 1), because the ratio $P$ in the current recommendations is 0 for sugar beet (the cost of fertilizer nitrogen is not taken into account) and 0.01 for potato (Anon., 1986). The recommended rates with REC C were derived from Neeteson \& Zwetsloot (1989; Tables 3 and 6). The recommendations used are shown in Tables 1 and 2. 


\section{J. J. NEETESON}

Table 1. Nitrogen fertilizer recommendations for sugar beet. $\mathrm{N}_{\text {rec }}=$ recommended rate; $\mathrm{N}_{\mathrm{m} 0-30}, \mathrm{~N}_{\mathrm{m} 30-60}$, and $N_{m 0-60}$ are the amounts of soil mineral nitrogen in the layers $0-30,30-60$ and $0-60 \mathrm{~cm}$, respectively. All amounts are expressed in $\mathrm{kg} \mathrm{N}$ per ha.

\begin{tabular}{llll}
\hline $\begin{array}{l}\text { Recommen- } \\
\text { dation }\end{array}$ & Soil type(s) & $\begin{array}{l}\text { Organic } \\
\text { manures }\end{array}$ & $\mathrm{N}_{\mathrm{rec}}$ \\
REC A & sand, loam, clay & no, yes & 126 \\
REC B & sand, loam, clay & no, yes & \\
& sand, loam, clay & green manures & $200-1.7 \mathrm{~N}_{\mathrm{m} 0-60}{ }^{2}$ \\
& & & $170-1.7 \mathrm{~N}_{\mathrm{m} 0-60}$ \\
REC C & sand & no & $205-0.8 \mathrm{~N}_{\mathrm{m} 0-30}-\mathrm{N}_{\mathrm{m} 30-60}$ \\
& loam & no & $175-0.8 \mathrm{~N}_{\mathrm{m} 0-30}-\mathrm{N}_{\mathrm{m} 30-60}$ \\
& clay & no & $180-0.8 \mathrm{~N}_{\mathrm{m0-30}}-\mathrm{N}_{\mathrm{m} 30-60}$ \\
& sand & yes & $155-0.8 \mathrm{~N}_{\mathrm{m} 0-30}-\mathrm{N}_{\mathrm{m} 30-60}$ \\
& loam & yes & $165-0.8 \mathrm{~N}_{\mathrm{m} 0-30}-\mathrm{N}_{\mathrm{m} 30-60}$ \\
& clay & yes & $140-0.8 \mathrm{~N}_{\mathrm{m} 0-30}-\mathrm{N}_{\mathrm{m} 30-60}$ \\
\hline
\end{tabular}

${ }^{1}$ With the exception of green manures.

${ }^{2}$ When $N_{m 0-60}$ is $100-150, N_{\text {rec }}$ is fixed at 30 ; when $N_{m 0-60}>150, N_{\text {rec }}$ is 0 .

${ }^{3}$ When $\mathrm{N}_{\mathrm{m} 0-60}$ is 85-135, $\mathrm{N}_{\text {rec }}$ is fixed at 30 ; when $\mathrm{N}_{\mathrm{m} 0-60}>135, \mathrm{~N}_{\text {rec }}$ is 0 .

Table 2. Nitrogen fertilizer recommendations for potatoes. See legend of Table 1 for meaning of $N_{\text {rec }}$ $\mathrm{N}_{\mathrm{m} 0-30}, \mathrm{~N}_{\mathrm{m} 30-60}$, and $\mathrm{N}_{\mathrm{m0}-60}$. All amounts are expressed in $\mathrm{kg} \mathrm{N}$ per ha.

\begin{tabular}{llll}
\hline $\begin{array}{l}\text { Recommen- } \\
\text { dation }\end{array}$ & Soil type(s) & $\begin{array}{l}\text { Organic } \\
\text { manures }\end{array}$ & $\mathrm{N}_{\text {rec }}$ \\
REC A & sand, loam, clay & no, yes & 286 \\
REC B & sand & no, yes & $350-1.8 \mathrm{~N}_{\mathrm{m} 0-30}$ \\
& loam, clay & no, yes & $320-1.1 \mathrm{~N}_{\mathrm{m} 0-60}$ \\
RECC & sand & no & $410-0.7 \mathrm{~N}_{\mathrm{m} 0-30}-0.3 \mathrm{~N}_{\mathrm{m} 30-60}$ \\
& loam & no & $320-0.7 \mathrm{~N}_{\mathrm{m} 0-30}-0.3 \mathrm{~N}_{\mathrm{m} 30-60}$ \\
& clay & no & $305-0.7 \mathrm{~N}_{\mathrm{m} 0-30}-0.3 \mathrm{~N}_{\mathrm{m} 30-60}$ \\
& sand & yes & $370-0.7 \mathrm{~N}_{\mathrm{m} 0-30}-0.3 \mathrm{~N}_{\mathrm{m} 30-60}$ \\
& loam & yes & $265-0.7 \mathrm{~N}_{\mathrm{m} 0-30}-0.3 \mathrm{~N}_{\mathrm{m} 30-60}$ \\
& clay & yes & $295-0.7 \mathrm{~N}_{\mathrm{m} 0-30}-0.3 \mathrm{~N}_{\mathrm{m} 30-60}$ \\
\hline
\end{tabular}

\section{Results}

\section{Recommended rates of fertilizer nitrogen}

For both sugar beet and potatoes the average recommended rate of fertilizer nitrogen was significantly $(P<0.001)$ lower with the current method (REC B) than with the fixed-rate method (REC A) or the refined current method (REC C) (Table 3). The difference was approximately $25 \mathrm{~kg} \mathrm{~N}$ per ha for sugar beet and $30 \mathrm{~kg} \mathrm{~N}$ per ha for potatoes. For sugar beet, the recommended fertilizer nitrogen rates of REC B 
Table 3. Recommended fertilizer nitrogen rate if various nitrogen fertilizer recommendation methods had been applied to sugar beet and potatoes. Average values of 150 sugar beet and 98 potato trials. Standard errors are given in parentheses. See Tables 1 and 2 for meaning of REC A, REC B, and REC C.

\begin{tabular}{lll}
\hline Recommendation & \multicolumn{2}{c}{ Recommended fertilizer nitrogen rate $\left(\mathrm{kg} \mathrm{ha}^{-1}\right)$} \\
\cline { 2 - 3 } & \multicolumn{1}{c}{ sugar beet } & potatoes \\
REC A & $126(-)$ & $286(-)$ \\
REC B & $98(3.77)$ & $257(5.07)$ \\
REC C & $120(3.13)$ & $288(5.48)$ \\
\hline
\end{tabular}

were about equally distributed between 25 and $175 \mathrm{~kg} \mathrm{~N}$ per ha, whereas the majority $(75 \%)$ of the recommended rates of REC C fell within a much narrower range, viz. between 100 and $175 \mathrm{~kg} \mathrm{~N}$ per ha (Fig. 2a). For potatoes the reverse was true: the recommended rates of REC C were about equally distributed between 200 and $400 \mathrm{~kg} \mathrm{~N}$ per ha, whereas $60 \%$ of the rates of REC B were between 250 and $300 \mathrm{~kg}$ $\mathrm{N}$ per ha (Fig. 2b).

\section{Yields obtained}

For both sugar beet and potatoes the highest average yields were obtained with REC C, but the differences from REC A and REC B were not significant. The difference was only $0.3-0.4 \mathrm{t} \mathrm{ha}^{-1}$ for sugar beet and $0.1-0.2 \mathrm{t} \mathrm{ha}^{-1}$ for potatoes (Table 4).

In Fig. 3, frequency distributions of the yield deficits are shown, i.e. the deviations of the yield from that obtained with the measured economically optimum amount of fertilizer nitrogen in each individual trial, if the various recommended rates of fertilizer nitrogen had been applied. In the calculations, 21 sugar beet and 24 potato trials were excluded, because the measured optima fell outside the range of fertilizer nitrogen levels tested. A deficit is negative when the yield obtained with a recommendation is higher than the yield at the measured optimum amount of fertilizer nitrogen. This occurred frequently with potatoes, because with any amount of fertilizer nitrogen larger than the optimum amount, yield is higher due to the asymptotic form of the response curve used for potatoes (normal exponential

Table 4. Yields of sugar beet and potato if various nitrogen fertilizer recommendation methods had been applied. Average values of 150 sugar beet and 98 potato trials. Standard errors are given in parentheses. See Tables 1 and 2 for meaning of REC A, REC B, and REC C.

\begin{tabular}{lll}
\hline Recommendation & \multicolumn{2}{c}{ Yield $\left(\mathrm{t} \mathrm{ha}^{-1}\right)$} \\
\cline { 2 - 3 } & sugar beet & potatoes \\
REC A & $63.7(0.86)$ & $56.9(0.87)$ \\
REC B & $63.8(0.89)$ & $56.8(0.88)$ \\
REC C & $64.1(0.86)$ & $57.0(0.88)$ \\
\hline
\end{tabular}




\section{frequency, \%}

\section{a}

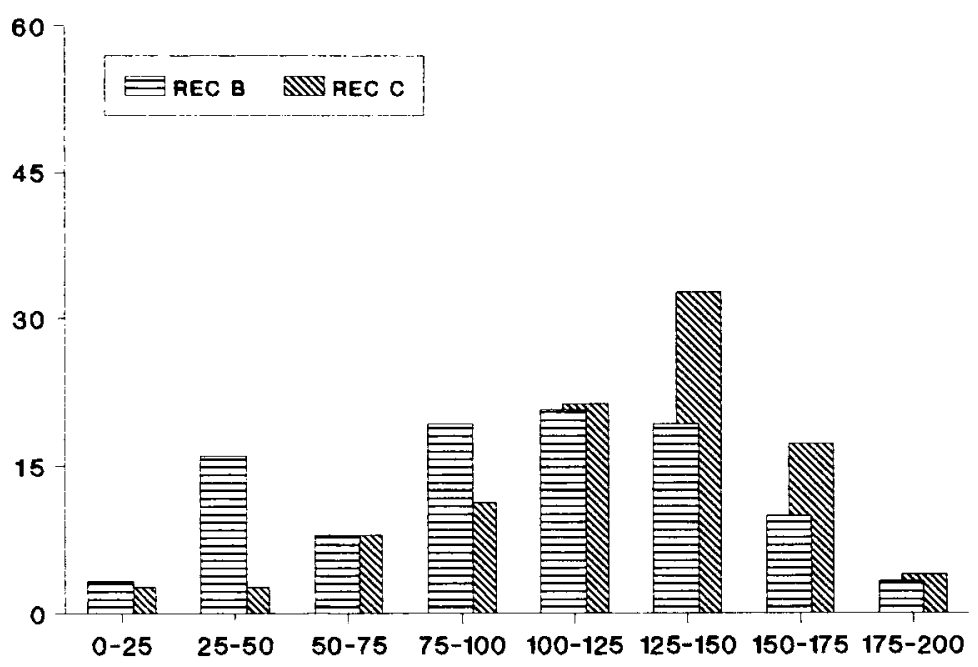

b

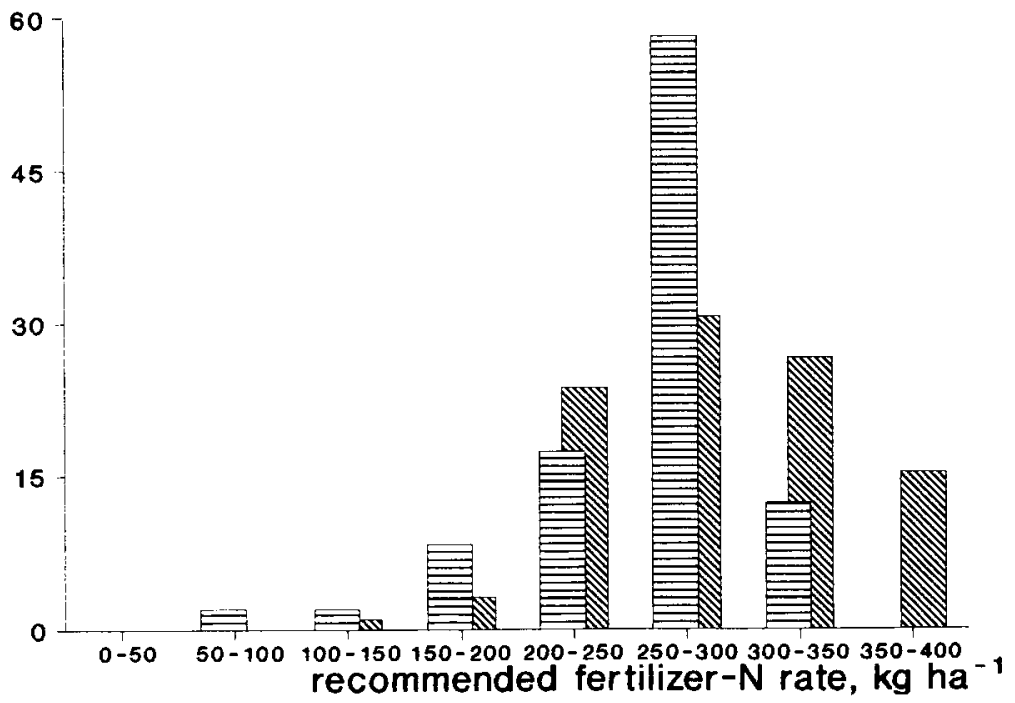

Fig. 2. Frequency distribution of the recommended fertilizer nitrogen rates for sugar beet (a) and potatoes (b) if REC B and REC C had been applied to 150 sugar beet and 98 potato trials. See Tables 1 and 2 for REC B and REC C. 


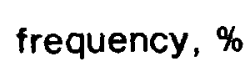

\section{a}
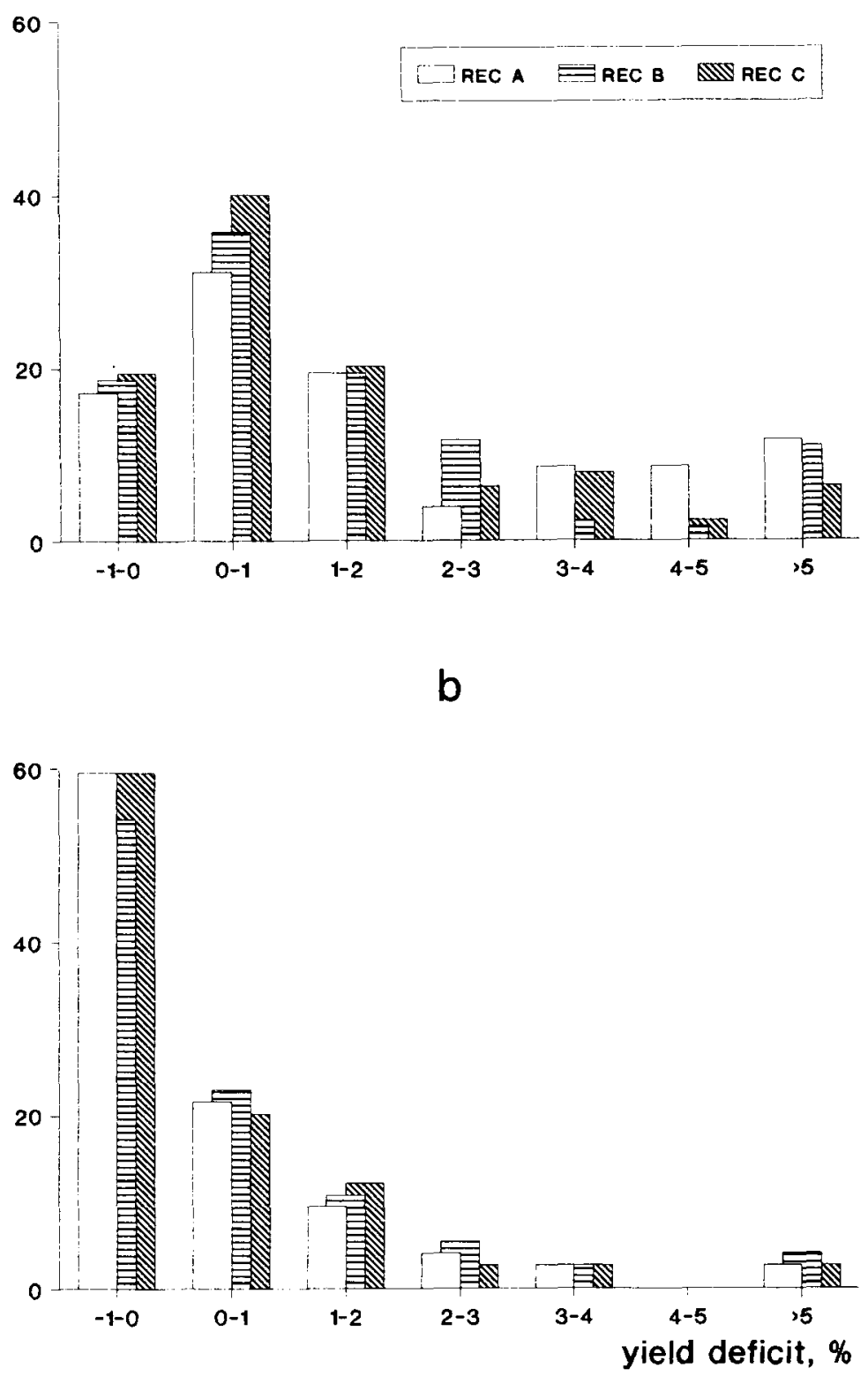

Fig. 3. Frequency distribution of the yield deficits for sugar beet (a) and potatoes (b) if REC A, REC B, and $\mathrm{REC} \mathrm{C}$ had been applied to 129 sugar beet and 74 potato trials. The yield deficits are expressed as a percentage of the yield obtained with the measured optimum application rate in the trials. See Tables 1 and 2 for REC A, REC B, and REC C. 


\section{J. J. NEETESON}

curve). When REC C was applied to sugar beet, the percentage of small yield deficits $(<2 \%)$ was highest $(80 \%$, as compared with $74 \%$ for REC B and $68 \%$ for REC A) and that of large yield deficits $(>5 \%)$ was lowest $(6 \%$, as compared with $11 \%$ for REC B and $12 \%$ for REC A) (Fig. 3a). For potatoes the frequency distributions of the yield deficits obtained with the various methods were similar. It is striking that the percentage of yield deficits less than $2 \%$ was about $90 \%$ (Fig. 3b).

All methods failed (yield deficits $>5 \%$ ) when there was a strong response to fertilizer nitrogen even though large amounts of soil mineral nitrogen were present in early spring ( $>100 \mathrm{~kg} \mathrm{~N}$ per ha in the $0-60 \mathrm{~cm}$ layer). In two trials with potatoes, all three methods failed when there was a negative response to fertilizer nitrogen although the soil contained only average amounts of mineral nitrogen in early spring (50-60 kg N per ha in the $0-60 \mathrm{~cm}$ layer), possibly due to accidental application of slurry in spring.

REC B and REC C gave good results with sugar beet, but REC A failed when the response to fertilizer nitrogen was weak or negative when large amounts of soil mineral nitrogen were present in early spring. In these situations, REC A grossly overestimated the amount of fertilizer nitrogen to be applied. REC A also failed when there was a strong response to fertilizer nitrogen at low levels of soil mineral nitrogen in early spring. The method then underestimated the amount of fertilizer nitrogen to be applied.

After application of organic manures, REC A and REC C showed good results with sugar beet, but REC $B$ failed when the response curve clearly declined beyond its maximum. The recommendation then overestimated the amount of fertilizer nitrogen to be applied, which sometimes resulted in serious yield depressions.

REC C for sugar beet failed only once when the other methods did not. It overestimated the amount of fertilizer nitrogen to be applied on a sandy soil where without application of organic manures a rather weak response to fertilizer nitrogen occurred despite a relatively low amount of soil mineral nitrogen in early spring ( $32 \mathrm{~kg}$ $\mathrm{N}$ per ha in the $0-60 \mathrm{~cm}$ layer).

\section{Recovery of fertilizer nitrogen}

The recovery of fertilizer nitrogen by sugar beet cannot be dealt with here, because the nitrogen contents of the crop or of parts of the crop were not measured.

In 96 potato trials the nitrogen contents in the tubers were measured at harvest. The average recovery of fertilizer nitrogen in the tubers is shown in Table 5 . It was

Table 5 . Fertilizer nitrogen recovery by the tubers if various nitrogen fertilizer recommendation methods had been applied to potatoes. Average values of 96 trials. Standard errors are given in parentheses. See Tables 1 and 2 for meaning of REC A, REC B, and REC C.

\begin{tabular}{ll}
\hline Recommendation & Fertilizer nitrogen recovery (\%) \\
REC A & $31(1.30)$ \\
REC B & $33(1.14)$ \\
REC C & $31(1.14)$ \\
\hline
\end{tabular}




\section{frequency, $\%$}

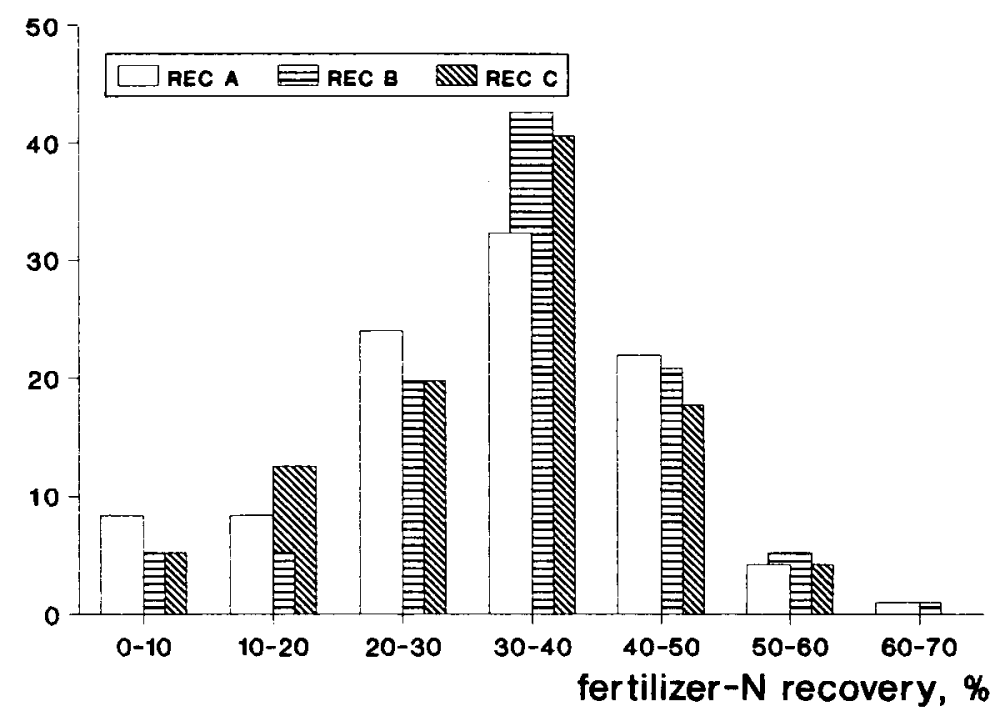

Fig. 4. Frequency distribution of the fertilizer nitrogen recovery by the potato tubers if REC A, REC $\mathrm{B}$, and REC C had been applied to 96 potato trials. See Tables 1 and 2 for REC A, REC B, and REC C.

highest when REC B had been applied, but the difference with REC A and REC C was not significant and was only $2 \%$. The frequency distribution of the recoveries (Fig. 4) shows that the variation in recovery was higher with REC A than with REC $\mathrm{B}$ and REC C. Very low recoveries (0-20\%) were generally obtained on fields where the amount of nitrogen in the tubers on plots without fertilizer nitrogen was large due to large amounts of soil mineral nitrogen in spring.

\section{Discussion}

\section{Prerequisites of nitrogen fertilizer recommendations}

A nitrogen fertilizer recommendation should be high enough to guarantee a high crop yield with a high fertilizer nitrogen recovery rate, and low enough to avoid money being spent on nitrogen not needed for high yields and liable to be lost due to leaching, resulting in environmental pollution. These two prerequisites are met when a recommendation accurately predicts the economically optimum application rate of fertilizer nitrogen, i.e. the minimum amount of fertilizer nitrogen needed for maximum profit. However, due to the large inaccuracy in the determination of the optima (Neeteson \& Wadman, 1987), in this paper a comparison of the various recommendation methods was not based on prediction of the optimum application rate of fertilizer nitrogen, but separately on the recommended amounts of fertilizer nitrogen and the yields obtained. 


\section{J. J. NEETESON}

Another reason why fertilizer nitrogen rates should be used judiciously is the saving of energy which is needed for the processing of fertilizers. The energy used for fertilizer production in the Netherlands constitutes approximately $10 \%$ of the total consumption of natural gas and $2 \%$ of the electric energy (Anon., 1988).

\section{Recommended rates of fertilizer nitrogen}

For sugar beet the rate of fertilizer nitrogen recommended by the current method was on average $25 \mathrm{~kg} \mathrm{~N}$ per ha lower than the rates recommended by the fixed-rate method and the refined current method. Only at low values of soil mineral nitrogen (less than approximately $25 \mathrm{~kg} \mathrm{~N}$ per ha in the layer $0-60 \mathrm{~cm}$, depending on soil type and application of organic manures) were the currently recommended rates higher than the other recommendations. However, the amount of soil mineral nitrogen in the $0-60 \mathrm{~cm}$ layer was usually larger than $25 \mathrm{~kg} \mathrm{~N}$ per ha, so generally lower fertilizer nitrogen rates were recommended by the current method.

For potatoes the current recommendation for fertilizer nitrogen to be applied was also lower than the other recommendations: on average $30 \mathrm{~kg} \mathrm{~N}$ per ha. The amount of fertilizer nitrogen currently recommended was smaller at any amount of soil mineral nitrogen in spring on sandy soils and smaller at moderate to large amounts of soil mineral nitrogen (more than approximately $30 \mathrm{~kg} \mathrm{~N}$ per ha in the 0 $60 \mathrm{~cm}$ layer) on loam soils without application of organic manures and on clay soils.

It should be noted here that the current recommendations for sugar beet and potatoes are not based on calculated response curves, but on hand-drawn curves. Moreover, the data set used for designing the current recommendations was not entirely identical to that used for the other two recommendation methods. In the design of the current recommendation method for sugar beet, trials in which organic manures had been applied were excluded; for potatoes, trials with industrial potatoes were included.

\section{Yields}

On average, there was no difference in the yields obtained with the various nitrogen fertilizer recommendations. Generally, all three methods predicted fertilizer nitrogen rates with which high yields were obtained. The response curves of sugar beet and potatoes generally consist of a short segment where yield rises sharply with increasing rates of fertilizer nitrogen and a large segment where yield varies little with increasing rates (e.g. Fig. 1). The presence of this long, flat segment implies that yields were quite similar for the various nitrogen fertilizer recommendations, but more so in the case of potatoes than sugar beet, because the response curve of potatoes does not decline at the higher rates of fertilizer nitrogen. Highest tuber yields would always have been obtained with $400 \mathrm{~kg}$ fertilizer nitrogen per ha. Obviously, applying a fixed rate of $400 \mathrm{~kg} \mathrm{~N}$ per ha would seldom have been profitable and would often have increased the risk of nitrate leaching.

In $6 \%$ (refined current method) to $11-12 \%$ (current method and fixed-rate method) of the trials, serious yield deficits $(>5 \%)$ were obtained with sugar beet. 
With potatoes it occurred in only $2-3 \%$ of the trials. All recommendations failed when there was a strong response to fertilizer nitrogen despite the presence of large amounts of soil mineral nitrogen in early spring. Presumably, errors were made in soil sampling, soil handling and/or soil analysis. Another explanation could be that in very wet springs, heavy nitrate leaching losses occurred in the interval between soil sampling or fertilizer nitrogen application and the start of nitrogen uptake by the crop (Whitmore et al., 1987). The trials in question were conducted in 1974 and 1981. Only the spring of 1981 (especially March and May) was actually wet, while the spring of 1974 was dry.

\section{Recovery of fertilizer nitrogen}

The recovery of nitrogen by the potato tubers was not significantly affected by the various methods of recommendation, but it was highest with the current recommendation. As recovery of fertilizer nitrogen generally is higher when fertilizer nitrogen rates are lower (Greenwood \& Draycott, 1988), the recovery was highest with the current method, because rates of fertilizer nitrogen recommended by this method were lowest. The recoveries were seldom higher than $50 \%$ and averaged 31-33\% (Fig. 4, Table 5). From the average recommended fertilizer nitrogen rates (Table 3 ) and the average recoveries by the tubers (Table 5), the recovery by the entire crop can be estimated. When it is assumed that the maximum amount of nitrogen in the tops plus tubers of the potato crop is 1.2 times the amount of nitrogen in the tubers at harvest (Neeteson et al., 1987), and that $20 \%$ of the total amount of nitrogen in the crop is present in the fibrous roots (Greenwood et al., 1985), it follows that the recovery of nitrogen by the entire potato crop was on average 46$50 \%$. The potato crop is apparently a rather inefficient user of fertilizer nitrogen. The usually poorly developed root system of the crop, together with its susceptibility to drought, are probably the main reasons for the low recovery of fertilizer nitrogen. When fertilizer nitrogen was applied at economically optimum amounts, at harvest about $30 \mathrm{~kg}$ more mineral nitrogen per ha was found in the soil than when no nitrogen had been applied (Neeteson et al., 1989). Sugar beet, however, is a more efficient user of fertilizer nitrogen. Fertilizer nitrogen recoveries by the tops plus beets are often found to be higher than $70 \%$ (Prins et al., 1988). Compared with no nitrogen fertilization, the additional amount of mineral nitrogen in the soil due to nitrogen application is usually negligible at the time of harvest (Lindén, 1987; Neeteson \& Ehlert, 1989).

\section{Practical implications}

For both sugar beet and potatoes the differences in performance between the methods were small, especially between the current and the refined current method. Similar results were found by Sylvester-Bradley et al. $(1987 \mathrm{a}, \mathrm{b})$ when they compared more or less refined nitrogen fertilizer recommendation methods for winter wheat. There is therefore no need to replace the current method by the refined one. Moreover, the refined method would have been more expensive, because soil min- 


\section{J. J. NEETESON}

eral nitrogen has to be measured in two layers instead of in one, as is the case with the current method. For sugar beet, where the contribution of soil mineral nitrogen in the $0-30 \mathrm{~cm}$ layer to the response to nitrogen is estimated to be $80 \%$ of that of fertilizer nitrogen and that in the $30-60 \mathrm{~cm}$ layer $100 \%$, the problem of determining soil mineral nitrogen in two layers could be overcome by measuring it in the $0-60 \mathrm{~cm}$ layer and assuming that its contribution to the response to nitrogen is $90 \%$ of that of fertilizer nitrogen.

The current method is to be preferred to the method of applying a fixed rate, because the former recommends a lower rate of fertilizer nitrogen without loss of yield.

The small improvement in the performance of the current and refined current methods, as compared with the fixed-rate method, is possibly attributable to the fact that the recommendations were made for average situations. The recommendations are too crude to be applicable to specific situations. Soil nitrogen mineralization rates during the growing season and yield levels, which have a strong impact on the fertilizer nitrogen requirement of a crop, may vary considerably from field to field. It is to be expected that site-specific nitrogen fertilizer recommendations can be given when explicit account is taken of nitrogen mineralization and crop growth. This can be done in a dynamic way with simulation models for the nitrogen cycle in the soil and for crop response to nitrogen. An example of such a model was given elsewhere (Neeteson et al., 1987).

\section{References}

Anon., 1986. Fertilizer recommendations for arable crops (in Dutch). Consulentschap voor bodem-, water- en bemestingszaken in de Akkerbouw en Tuinbouw, Wageningen, 28 pp.

Anon., 1988. Statistical reference book (in Dutch). Centraal Bureau voor de Statistiek. Staatsuitgeverij, Den Haag, 421 pp.

Dilz, K., 1981. The nitrogen fertilization of spring barley. Plant and Soil 61: 269-276.

Greenwood, D. J. \& A. Draycott, 1988. Recovery of fertilizer-N by diverse vegetable crops: processes and models. In: D. S. Jenkinson \& K. A. Smith (Eds), Nitrogen efficiency in agricultural soils, p. 4661. Elsevier Applied Sciences, London.

Greenwood, D. J., J. J. Neeteson \& A. Draycott, 1985. Response of potatoes to N fertilizer: quantitative relations for components of growth. Plant and Soil 85: 163-183.

Lindén, B., 1987. Reasons for variations in optimum demand of fertilizer nitrogen in sugar beet production. In: N. E. Nielsen (Ed.), Proceedings 3rd Meeting NW European study group for the assessment of nitrogen fertilizer requirement, p. 72-87. The Royal Veterinary and Agricultural University, Copenhagen.

Neeteson, J. J., 1985. Effectiveness of the assessment of nitrogen fertilizer requirement for potatoes on the basis of soil mineral nitrogen. In: J. J. Neeteson \& K. Dilz (Eds), Assessment of nitrogen fertilizer requirement, p. 15-24. Institute for Soil Fertility, Haren.

Neeteson, J. J. \& P. A. I. Ehlert, 1989. Environmental aspects of applying inorganic fertilizers to sugar beet. Proceedings 52nd Winter Congress. International Institute for Sugar Beet Research, Brussels (in press).

Neeteson, J. J. \& W. P. Wadman, 1987. Assessment of economically optimum application rates of fertilizer $\mathrm{N}$ on the basis of response curves. Fertilizer Research 12: $37-52$.

Neeteson, J. J. \& H. J. C. Zwetsloot, 1989. An analysis of the response of sugar beet and potatoes to fertilizer nitrogen and soil mineral nitrogen. Netherlands Journal of Agricultural Science 37: $129-141$. 
Neeteson, J. J., K. Dilz \& G. Wijnen. 1989. N-fertilizer recommendations for arable crops. In: J. C. Germon (Ed.), Management systems to reduce impact of nitrates. EEC, Brussels (in press).

Neeteson J. J., D. J. Greenwood \& A. Draycott, 1987. A dynamic model to predict yield and optimum nitrogen fertiliser application rate for potatoes. Proceedings 262. The Fertiliser Society, London, 31 $\mathrm{pp}$.

Prins, W. H., K. Dilz \& J. J. Neeteson, 1988. Current recommendations for nitrogen fertilisation within the EEC in relation to nitrate leaching. Proceedings 276. The Fertiliser Society, London, $27 \mathrm{pp}$.

Sylvester-Bradley, R., T. M. Bloom, L.V. Vaidyanathan \& A. W. A. Murray, 1987a. The quest for the optimum: a comparison of nitrogen recommendation systems for winter wheat. In: N. E. Nielsen (Ed.), Assessment of nitrogen fertilizer requirement, p. 113-133. The Royal Veterinary and Agricultural University, Copenhagen.

Sylvester-Bradley, R., T. M. Addiscott and L. V. Vaidyanathan, A. W. A. Murray \& A. P. Whitmore, 1987b. Nitrogen advice for cereals: present realities and future possibilities. Proceedings 263 . The Fertiliser Society, London, $36 \mathrm{pp}$.

Tinker, P. B. H., 1965. The effects of nitrogen, potassium and sodium fertilizers on sugar beet. Journal of Agricultural Science (Cambridge) 65: 207-212.

Whitmore, A. P., G. F. J. Milford \& M. J. Armstrong, 1987. Evaluation of a nitrogen leaching/mineralization model for sugar beet. Plant and Soil 101: 61-65. 